\title{
Extending clothing lifetimes: an exploration of design and supply chain challenges.
}

\author{
Lynn Oxborrowa ${ }^{a}$ Stella Claxton ${ }^{b}$

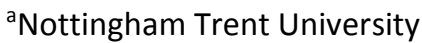 \\ bottingham Trent University \\ *Corresponding author email: Lynn.oxborrow@ntu.ac.uk
}

\begin{abstract}
The environmental impact of clothing could be reduced if average garment lifetimes were increased. The paper explores the design and supply chain implications of clothing longevity, adapting models from sustainable clothing design research, and evidence from interviews and expert roundtables. The research concludes that the process of design for longevity could be adopted by clothing retailers and brands, but that the principles behind adopting this strategy lack credence in industry, because the mandate to do so, and robust business models, are lacking. The paper identifies a range of conflicting priorities between commercial and sustainable practice that must be addressed to reduce the environmental impact of clothing by extending its useful life, and makes recommendations for industry and future research. However, the limitations to adopting more sustainable practice relate to fashion and market segment, are systemic within the clothing supply chain and attempts to resolve these require a commercial imperative.
\end{abstract}

Keywords: Clothing longevity; sustainable design; supply chain management; new product development

The deadline to submit your final paper is midnight on $16^{\text {th }}$ March 2016. Submit your paper to the conference review system at https://www.conftool.pro/drs2016.

Current 4707

\section{Introduction}

Designing clothing that has a useful lifetime, extended beyond current norms, could help to reduce excessive, unsustainable product disposal and waste. However, for retailers to 
enhance clothing longevity would require the simultaneous adoption of new business models to reduce any impact on competitiveness (WRAP, 2012a), updated design practices to underpin both technical and emotional durability of clothing, and changes to consumer expectations and behaviour. To date, research has shown that, although over a third of the population claim that they could buy more clothes that are 'made to last' and would like to do so (WRAP, 2012b), there is limited evidence that this view is shared by industry strategists.

The paper uses evidence from interviews and round table discussions with clothing industry stakeholders to explore the conflicting priorities, perceptions and tensions between commercial and sustainable practice in this emerging field. It goes on to discuss the drivers exerted on the new product development process and consequences for the supply chain that would be necessary to address the commercial, technical and design aspects of reducing the environmental impact of clothing through extending its useful life.

The research on which the paper is based was undertaken for Defra (UK Department for Environment, Fisheries and Rural Affairs) and aims to identify ways to identify and overcome the problematic trade-offs concerned with extending clothing life-times and make recommendations for industry and future research.

\section{Review of existing literature}

Longevity of clothing takes into account durability as well as user behaviour and wider sociocultural influences (Cooper, 2010). Drawing upon this understanding of longevity, a review of recent studies explored issues associated with clothing longevity from technical and consumer perspectives, as well as the commercial aspects of designing new clothing products and the clothing supply chain.

\subsection{Clothing longevity: technical and consumer considerations}

Discarded clothing accounts for around 5\% of total UK household waste, even though carbon, water and waste footprint studies indicate that extending the useful life of clothing, assuming this reduces product sales, could effectively reduce negative life-cycle impacts (WRAP, 2012). Most of these impacts are embedded in clothing production, rather than its use and care, and the WRAP report (2012) concluded that extending the active usage of clothing by an average of three months would reduce its carbon, water and waste footprint by $5-10 \%$, while extending average clothing lifetime by one third could reduce its environmental footprint by over $20 \%$ (ibid). However, at present a range of fabric, component, construction and colour failures restrict clothing lifetimes, even though these are often avoidable (WRAP, 2014). WRAP (2012) estimates that $1.7 \mathrm{~m}$ tonnes of materials are used annually to make some $1.14 \mathrm{~m}$ tonnes of finished clothing in the UK. Of this $0.9 \%$ is wasted through premature product failure, and $48 \%$ discarded for re-use, but some $31 \%$, or 350,000 tonnes, of used clothing is added to landfill every year. Designing products for longer lifetimes has therefore become a UK Government policy objective to minimise 
clothing sent to landfill, as well as reduce the amount of clothing waste produced through unnecessary production and early product failure. An assumption that longevity need not have a negative commercial impact if appropriate business models and pricing strategies are adopted is central to this policy (WRAP, 2013b) but appears to be at odds with the view of some clothing industry strategists.

However, research into consumer behaviour and expectations suggests that consumers, particularly the young, make increasingly regular purchases (Fisher et al., 2008) of low price, lower quality (Leonard, 2008), fast turnaround clothing (Black, 2008) and discard items they consider out of fashion (WRAP, 2012). While in the WRAP report (2012) only $21 \%$ of consumers said they consider the latest trends in fashion as influential when buying clothes, some $58 \%$ of $16-24$ year olds admitted to owning clothes they consider too out-of-fashion to wear. Meanwhile, $57 \%$ of consumers owned clothes that remained unworn because they no longer fit (WRAP, 2012).

Concern surrounding issues associated with fast fashion is increasingly evident from some retailers, consumers and media commentators (Muton, 2012). However, concerned consumers, primarily mature women who favour durable clothing and are influenced by the relationship between price, quality and value (Mintel Oxygen, 2011; WRAP, 2012; Fisher et al., 2008), create an opportunity to increase the longevity of classic items in particular. Furthermore, the relative importance of fit in determining clothing use suggests that design for adaptation and alteration is a potentially important contributor to clothing longevity, while schemes for clothing buy-back and re-use (WRAP, 2012) can help clothing lifetimes to be extended as an alternative to disposal in landfill.

Increased garment longevity would clearly require changes in industry practices. For example, testing for product longevity by carrying out extended wearer trials can help product developers to make decisions that avoid or delay garment failure (Cooper et al., 2014), but the cost and time taken can be prohibitive. However, extreme durability testing for outdoor and sports clothing, and other recent advances in testing that could fit better with the supply chain's speed and cost imperatives and better reflect consumer behaviour, are now available (Annis, 2012; Cooper et al., 2014).

\subsection{Sustainable clothing design}

New product development (NPD) of clothing incorporates idea generation, market screening, commercialisation of concept and technical developments, leading to the design and specification for each clothing item (Swink, et al., 2010). NPD is an important contributor to clothing sustainability as some $80 \%$ of clothing's environmental impact is determined at the design stage (Defra, 2011). Sustainable design requires multi-disciplinary co-operation between designers, merchandisers, business strategists, production teams, marketing staff, end of life and corporate responsibility managers in order to achieve both customer value and sustainable design (Hong, 2009; Curwen et al., 2012). This must be underpinned by organisational values and ethos, as well as a systems thinking approach to addressing all 
perspectives holistically (Hong et al., 2009) if those involved in NPD are to be able to act effectively. Allwood et al., (2008) conclude that the environmental impact of clothing is greater from use and maintenance than from materials and production, and that this should be reflected at the design stage. However, customer value, and cost must figure alongside sustainability metrics during the design process (Huang et al., 2009).

Based on established mapping of clothing design processes, Gam et al.'s (2008) C2CAD model for sustainable clothing design adopts such a collaborative approach, using the 'cradle to cradle' closed loop design strategy (McDonagh and Braungart, 2002), breaking down products into 'nutrients' that are recycled through a technical or biological system to achieve a net environmental benefit. The model has four main steps: problem definition and research; sample making; solution development and collaboration; and production. The first phase results in an initial design, taking into account functional, aesthetic and economic needs, while sample making focuses on identifying and testing resources, identifying their cost and potential environmental impact (in terms of biological or technical nutrients) as well as evaluating the product's marketability, ease of production and post-use pathways. To achieve solutions and collaboration, Gam et al.'s model suggests that the network of suppliers should be engaged in information sharing to address issues with materials, design and consumption. The final stage is production, which should consider materials and resource usage and emissions, as well as efficiencies, quality and reliability.

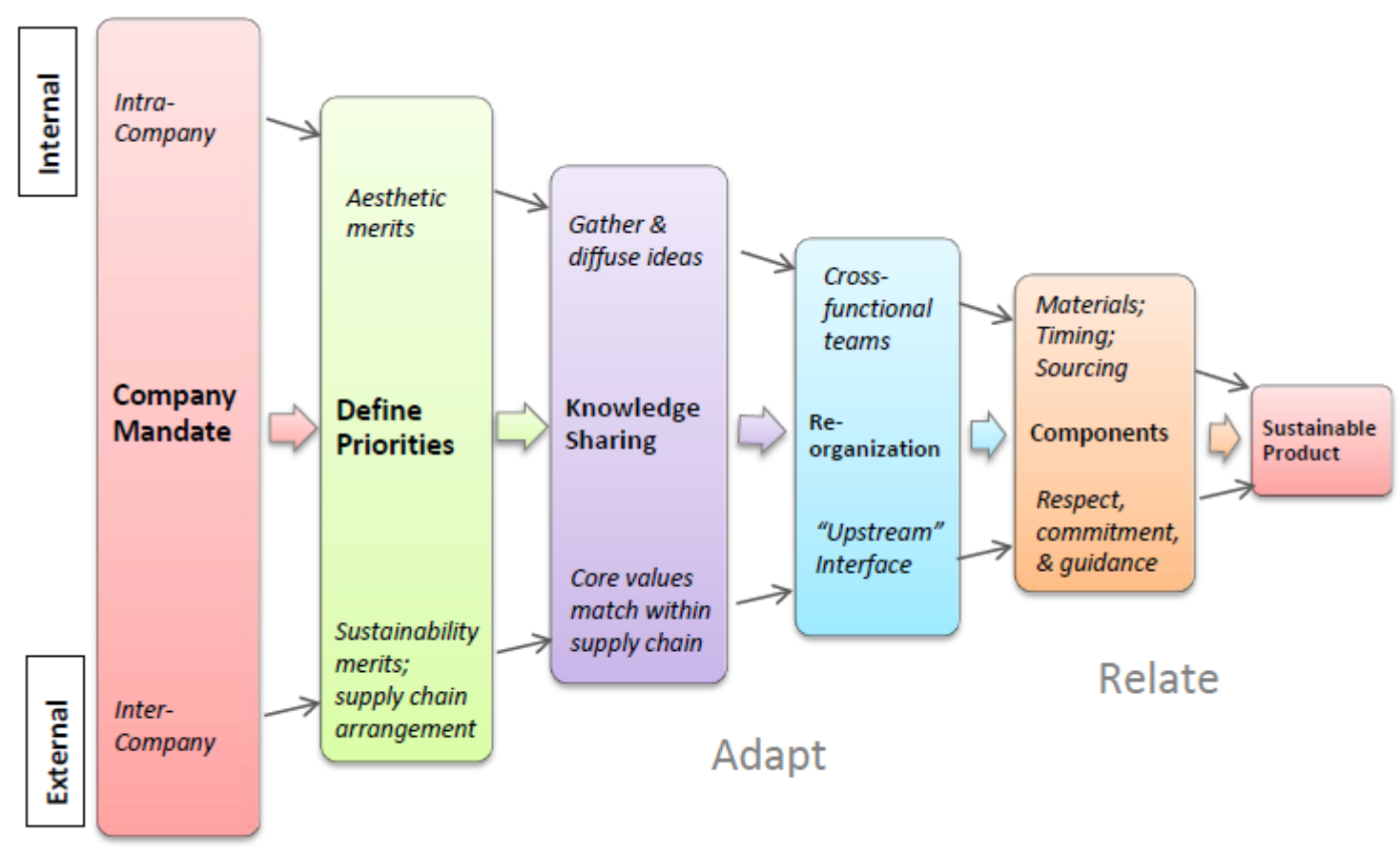

Define

Figure 1 Sustainable Design Process Map: based on the principles behind Eileen Fisher's Peru Project (Curwen et al., 2012) and its upstream supply chain. Illustrated by the authors. 
The collaborative aspect of sustainable design is further developed in a later applied case study, based in a real business setting. Curwen et al. (2012) reported that the company, Eileen Fisher, found it necessary to compromise on the breadth of ranges designed, but otherwise achieved their sustainable objectives by enabling designers to benefit from a proactive business culture, objectives, structure and processes that support sustainable design. This culture enabled designers to have direct communications with suppliers to make best use of their capabilities, and facilitated numerous cross-functional teams to implement improvements. Based on this experience, Curwen et al. (2012) identified five principles of design for sustainable clothing: company mandate, shared values, knowledge sharing, reorganisation and supply chain simplification, as illustrated in Figure 1.

\subsection{Designing clothes that last for longer}

Clothing products have an average lifetime of 3.3 years, although there is considerable variation between different types (WRAP, 2012b). While some items are reused, or recycled, many discarded items end up in landfill because they are deemed to be too damaged or worn out. While the UK Sustainable Clothing Action Plan (SCAP) seeks to reduce the environmental impacts of clothing supply it is based on the assumption that extending garment lifetimes should not be commercially detrimental and could help to increase brand value, and this challenge has become of increasing relevance to subsequent projects.

Subsequent research (WRAP, 2014; Claxton et al., 2015) reflected on the development and trial of a 'Longevity Protocol', combining a 'best practice' approach to product development with physical tests to provide an indication of life expectancy for specific garment types, for use by retailers and the clothing sector more widely to support commercial implementation. The Protocol addressed the call from retailers for a more standardised approach to testing for longevity. Claxton et al. (2015) concluded that further research was necessary to ensure that tests could better represent consumer behaviour and could be time-compressed to enable longevity testing in a manner more sympathetic to the pressured new product development cycle for clothing.

Much of the UK research has focused attention on clothing lifetimes on the physical performance of the clothing items. An alternative perspective is that design for clothing longevity should lengthen the emotional attachment between consumers and clothing items, so that use is for longer and greater care taken (Laitala and Boks, 2012; Niinimäki, 2012; Niinimäki and Armstrong, 2013). To achieve this aspect of longevity, known as emotional longevity or durability, it is necessary to enhance product satisfaction by designing in features that provide the benefits that accrue from longer use, such as flexibility to changing fit, emerging trends and individual style and to redefine the service-product mix. However, this requires a systems thinking and more pro-active, visionary and far-sighted design approach (Laitala and Klepp, 2011; Niinimäki, 2012). Such an approach needs to apply to the acquisition, maintenance and disposal of clothing, and business model innovations 
such as swapping, rental, redesign, repair, customisation and style/skills advice could extend garment life (Armstrong et al., 2014; WRAP, 2013b). Laitala and Klepp (2011) also acknowledge that very short life-cycle, fashion products need to be more easily recyclable. However, design for clothing longevity research is prescriptive regarding what should be achieved, but lacks the practical detail of how this could be realised that appears in models such as those of Gam et al. (2008) and Curwen et al. (2012).

\subsection{New product development and the clothing supply chain}

Curwen et al. (2012) stress the importance of cultivating strong supply chain relationships to SC design, while others stress the importance of supplier selection and capability to support the NPD process (Petersen, Handfield, and Ragatz, 2005) and the significance of knowledge sharing and trust among competitive and cooperative firms in sustainable supply chains (Cheng, Yeh, \& Tu, 2008). In addition, solving sustainability problems by implementing strategies such as early supplier involvement, information sharing and integrative product development have been acknowledged (Kogg, 2003; McDonough et al., 2003; Petersen, Handfield, \& Ragatz, 2005).

In practice, the multiple interests contributing to the NPD process may cause delays in the supply chain through indecision associated with conflicting priorities and functional constraints of the design and technical staff, marketing, purchasing, production, sourcing and finance roles of retailers and brands, all compounded by the trend for rapid proliferation of fashion products and globalisation of supply. Armstrong and LeHew (2011) suggest that fast fashion is a partly sustainable supply chain solution because it regulates supply in line with demand and limits material use and inventory. This is contrasted to the concept of slow design and design activism which requires a rethink of the relationship between consumers and their products, but is not specifically applied to fashion, and would require a resolution to the conflict in costing ethos of market price rather than ecological value in clothing and rapid new product demands, rather than product improvement. Models such as that by Gam et al. 2008 go some way to bridging the gap by broadening the problem definition stage from purely commercial and aesthetic to include ecology.

However in practice, in spite of the spread of fast fashion, which depends on fast decision making, shorter lead-times and reduced sampling, aided by use of virtual technologies (Cachon and Swinney, 2011; Khan et al., 2012), the demands of design and brand integrity result in slow decision making and added product testing (Brun and Castelli, 2008), reinforcing a resistance to innovative design practices that could shorten the design or manufacturing process (Oxborrow, 2015). Caniato et al. (2012) found two different approaches to environmental sustainability performance. Large companies tend to focus more on incremental products and process improvement, whereas small companies have been able to completely reshape their supply chain.

Early supplier involvement in the design process, while it can shorten lead times and reduce costs, is in practice used to compensate for the increasingly slow and low cost global supply 
that has become the industry norm (Khan et al., 2012; Scheffer, 2012). Meanwhile Aage and Belussi (2008) found that globalisation of firms has fragmented the clothing industry clusters hitherto able to acquire fashion and technical knowledge. Barriers to the adoption of sustainable design and supply chain practices include lack of transparency, data reliability and influence over upstream suppliers (Rauer and Kaufmann, 2015).

This paper goes on to explore the barriers, including technical limitations, conflicting priorities, perceptions and organisational tensions that hinder the adoption of design and supply of longer lasting clothing. It then discusses ways in which the commercial, technical and design limitations of reducing the environmental impact of clothing through extending its useful life can be mitigated.

\section{Methodology}

The research draws on 25 interviews with industry representatives from UK clothing retailers, brands, suppliers and service providers; three expert roundtable discussions bringing together industry and academic specialists and a thought-leaders' workshop comprised of multi-disciplinary academic and industry experts. Interviews were face-to-face or by phone, lasted one hour on average. The roundtables and workshop lasted 2.5 to 3.5 hours; the roundtables involved on average 6 contributors, while the workshop involved 26 participants, and collectively they covered the significance of product development and testing, garment failure (commonly pilling) and consumer perspectives on clothing longevity, and the business case. All activities were recorded and transcribed. Findings have been analysed using a framework based on Gam et al.'s (2008) paper and Curwen et al.'s (2012) case study.

\section{Findings and Analysis}

The findings follow two principal themes, based on the authors' initial evaluation of the design and supply chain challenges to extending the useful life of clothing and on the models for designing sustainable clothing discussed above. In the first instance, Gam et al's (2008) model is adapted to accommodate the stages of design for longer lasting clothing. Illustrated in Table 1, this model takes into account the "what needs to be done" or physical aspects of extending the lifetime of clothes. Subsequent analysis builds upon the experiential model developed by Curwen et al. (2012) which is discussed below before the findings are compared. 


\subsection{Design for Clothing Longevity - key stages}

Table 1 Stages of Design for Clothing Longevity - Adapted from Gam et al, (2008)

\begin{tabular}{|c|c|}
\hline Design stage & Aspects relating to clothing longevity \\
\hline \multirow[t]{3}{*}{ Problem definition } & $\begin{array}{l}\text { Consumer perceptions represent emotional attachment and desire } \\
\text { to change }\end{array}$ \\
\hline & The business case is poorly defined in most organisations \\
\hline & Slower fashion niche: quality equates to durability \\
\hline \multirow[t]{3}{*}{ Sample making } & Sourcing durable materials \\
\hline & Testing \\
\hline & Impact on cost, time, environment, etc. \\
\hline \multirow{4}{*}{$\begin{array}{l}\text { Solution } \\
\text { development }\end{array}$} & Engages suppliers' skills and knowledge \\
\hline & Trust/ lack of trust \\
\hline & Extended testing is hard to implement \\
\hline & Addition of services such as repair \\
\hline \multirow[t]{5}{*}{ Production } & NPD and testing regime does not fit into critical path \\
\hline & Mass produced garments do not always represent tested samples \\
\hline & Requires change to product/service mix \\
\hline & $\begin{array}{l}\text { Potential to use less production resources: reduced consumption } \\
\text { of higher quality clothing }\end{array}$ \\
\hline & $\begin{array}{l}\text { Contrast with overall sustainable design objectives: making a } \\
\text { difference depends on early process stages. }\end{array}$ \\
\hline
\end{tabular}

The findings show that in general terms, each stage of the design process for developing and producing longer lasting clothing can be supported to some extent by practice. The problem can be clearly defined, and for some consumers durability is a desirable garment quality, provided that they also have a desire or reason to keep and use clothing items for longer. More contentious is how this translates into the business case. Some of the retail/brand respondents claimed that durability enhances brand value, while one high value supplier was negative about the commercial case for durability and there is no clear correlation between those supporting durability and market level of brand. Furthermore, some industry participants were sceptical about the concept of emotional durability, referring only to aspects of comfort and fit to foster attachment to specific items.

The sample making stage can be supported by sourcing materials that are durable and promote garment longevity, and findings show that testing both materials and finished garments supports initial quality and fitness for purpose reasonably well. Some suppliers express concern that poor durability leads to high return to manufacture (RTM) rates which are costly and damage their reputation with retail buyers. In contrast, some garments regularly fail tests, notably knitwear and sublimation printed jerseys. These are among items commonly accepted for resale anyway, because of commercial imperatives. For example, fast fashion suppliers expected their products to fail tests for pilling and other 
characteristics, while commercial pressure means that problems are not addressed. Therefore, testing of both materials and finished garments for longer life is an obstacle as most testing regimes support initial quality and fitness for purpose for one to five wash cycles only, and adding additional or extended tests both adds to cost and causes delays to the critical path. One supplier anticipated that testing will increasingly be carried out at supply locations in the Far East, while testing experts acknowledged the lack of a commercial imperative to upgrade and develop new tests to reduce time delays and improve objectivity and effectiveness.

Solution development is another stage where conflicts are apparent. While it is desirable to engage supplier skills and knowledge to improve access to upstream materials there are barriers to doing so, and some respondents report a lack of skills within the supply chain. There is also evidence of a lack of trust, which affects both exchange of information/ knowledge and practical steps such as quality assurance and testing processes. Several suppliers suggested that their recommendations of fit-for-purpose fabrics, yarns or finishes were sometimes over-ruled in favour of less durable options.

Production is arguably the least well-developed aspect of design for longevity, as the limitations identified above are exacerbated by the challenges of bulk production, in terms of scheduling and potentially conflicting priorities, such as use of higher grade materials and supplier trust. However, the production of higher quality clothing for longer use is possible if the preceding stages can be resolved.

\subsection{Implementing Design for Clothing Longevity}

Given the obstacles facing some specific stages in the development of longer life clothing, it is also important to explore the principles behind the design for longevity and the obstacles to adopting these. Based on Curwen et al.'s (2012) model, Table 2 summarises the key principles concerned with the implementation of, or "how to" approach to design for clothing longevity.

Table 2 Principles of design for clothing longevity-adapted from Curwen et al. (2012)

\begin{tabular}{ll}
\hline Design Principle & Aspects relating to clothing longevity \\
\hline Company Mandate & $\begin{array}{l}\text { Participants are signatories to SCAP } \\
\text { Sustainability managers/ representatives in place } \\
\text { Sustainability objectives evident include supplier codes, waste } \\
\text { metrics, fibre scorecard }\end{array}$ \\
\hline $\begin{array}{l}\text { Shared values within } \\
\text { and between }\end{array}$ & $\begin{array}{l}\text { Focus on aesthetics and/or cost } \\
\text { companies }\end{array}$ \\
\hline 'Blame' attributed to supplier and/or consumer \\
Knowledge sharing & $\begin{array}{l}\text { Lack of skills/knowledge or limited by confidentiality } \\
\text { Lack of technical knowledge relating to product/component } \\
\text { environmental impacts }\end{array}$ \\
\hline
\end{tabular}




\begin{tabular}{ll}
\hline & Complex, confusing, care instructions inconsistent with consumer \\
& practice, laundry appliances and product test protocols \\
\hline Re-organisation & Lack of time/ capacity and capability; \\
& Sustainability implementation led by individuals \\
& Limited intra-organisational project teams and lack of inter- \\
& organisational teams addressing longevity projects \\
\hline Supply chain & Global and complex; long and slow; buyer dominated; \\
& Lack of transparency within supply chain; \\
& Focus on product proliferation, cost and volume. \\
\hline
\end{tabular}

The findings show that the retailers and brands are likely to be UK Sustainable Clothing Action Plan (SCAP) signatories, but that longevity of products is not the focus of their sustainability objectives, and as a result designers and NPD teams lack a mandate to focus on extending clothing life specifically. At the same time, while sustainability generally is considered a strategic priority, it is poorly integrated into other functions and is of low priority when compared to cost and aesthetics. Of equal concern, the researchers found a lack of "agency" with regard to clothing longevity, with blame extended to consumers with regard to their clothing care and suppliers with regard to inferior materials and garment quality, even though the supply chain is, in the main, controlled by retailers and brands. The expert panel concluded that the capacity of design teams to make changes is often influenced by organisational structure, with small company designers able to represent the whole NPD process but lacking financial resources, while the design team in a large company may lack strategic influence.

The lack of trust and agency across the supply chain combine to create barriers to the sharing of knowledge. While the UK suppliers interviewed were able to evidence high levels of technical knowledge, global fragmentation of the supply chain has created both physical and cultural barriers to established knowledge sharing and problem solving practices. This extends both upstream and downstream in the supply chain, including sharing of accurate and realistic guidance with consumers relating to product care. Furthermore, respondents suggest that some suppliers take advantage of the distance between themselves and their customers to disguise or even falsify information regarding quality tests and upstream supply. Round-table participants identified cases where inferior materials and processes have resulted in shorter fibres more likely to pill or lower cost dyes which leach more readily. The commercial trade-off between product quality, durability and other garment/fabric characteristics, aesthetics and price, combine with pressure on the critical path timeline to undermine the case for durability. Lack of traceability upstream in the supply chain can also limit the level of detailed technical information available.

Correspondingly, the level of re-organisation required to establish multi-functional teams within and between organisations is severely limited, with suppliers reporting contradictions in their relationships with different divisions of their retail customers (such as head office 
and overseas sourcing offices). Finally, in direct contrast to the example cited by Curwen et al. (2012), the supply chain for clothing is generally global, and consequently long, complex and lacking transparency.

\section{Discussion}

Evaluating design for clothing longevity therefore throws up a number of issues that appear difficult to resolve, but that need to be overcome if extending clothing life is seen as a potential solution to the amount of clothing that finds its way to landfill, consistent with WRAP strategy (2012). In some organisations, the mandate to promote sustainability does not encompass extending clothing lifetimes as this does not fit into existing key performance measures (KPIs) in the same ways as energy efficiency and is indeed hard to measure. As discussed by Caniato et al. (2012) the researchers found that, in terms of shared values, cost or commercial drivers and aesthetics are considered much more important and therefore influence strategic decisions more directly. While fast-fashion items are synonymous with short lifetimes, for high value brands product failure compromises brand values (Brun and Castelli, 2008) and for everyday items, such as schoolwear, guaranteed product lifetimes are a means to compete in a crowded market (Cooper et al, 2014). Furthermore, emotional attachment is essential to ensure that products stay in active use for longer, as discussed at length by Niinimäki and Armstrong (2013), Niinimäki (2012) and Laitala and Boks (2012). Because of the lack of strategic focus, the business model has not yet been found that can elevate clothing longevity, for those items with potential for extended use, to a matter of commercial importance on any significant scale (ibid).

Because of this lack of mandate, other practices considered to be leading edge in design and supply chain management are of limited application in clothing and not specifically applied to the pursuit of longer lasting clothes. These include overcoming the gap in knowledge created by global fragmentation of the supply chain (Aage and Belussi, 2008) and developing trusting relationships with suppliers (Peterson et al, 2005). Exchange of knowledge with consumers is also inhibited or confusing (McLaren et al., 2015) and it is clear that usercentred design that takes into account the way that consumers wear and care for clothing is rarely considered, even though it could help consumers to extend the life of their clothing (WRAP, 2012). The organisation of change initiatives is limited, sometimes to informed or passionate individuals rather than cross-functional teams, and to sustainability generally, rather than product lifetimes specifically. Moreover, researchers have found little evidence of functional inter-organisational teams, certainly not to the extent described by Curwen et al. (2012). Consequently, suppliers are rarely if ever involved in the problem definition stages of new product development as advocated by both design and supply chain schools of thought (Cheng et al, 2008; Khan et al, 2012; Peterson et al., 2005), and the historical problem-solving capability reflected on by some respondents has not been replicated within their global supply chains as restructuring has taken place. The effect of this is exacerbated by both lack of trust (Cheng et al. 2008) and abuse of trust. Furthermore, the supply chain is subject to poor transparency and traceability, consistent with findings of Rauer and 
Kaufmann (2015), issues which affect all aspects of sustainability. It is important to note that many of these limitations are generic within the clothing supply chain, and considered systemic because of their persistence (Oxborrow, 2015). The lack of a clear mandate and commercial pressure to implement strategies relating to clothing longevity seem unlikely to breakdown such inherent limitations.

\section{Conclusions and recommendations}

The paper concludes that the process stages to develop longer lasting clothing are operational, but that implementation is incomplete and sporadic, with other priorities taking precedence - including more obvious aspects of sustainability. The limited effectiveness of such processes can be attributed to a wide-scale failure to adopt the principles necessary to implement strategies that could support clothing longevity. Because of a failure to justify a robust business case, there is no clear mandate for designers and NPD teams to follow, and no real incentive to overcome the systemic failures within the clothing design and supply chain. While there are signs that policy organisations are encouraging retailers and brands to rethink their priorities and broaden their definitions of sustainability, progress is slow and small scale, and at present inadequate to keep pace with changes in the market, or to impact globally on the environment. Furthermore, improving a more integrated approach to design for clothing longevity should account for a range of product/garment and brand options regarding lifetime expectations, re-use and recycling. This could include ease of recycling for fast fashion or facilitating longer active use for higher value and core products.

The paper is limited to a relatively small scale study, based within the UK. While there is evidence of research from other parts of Europe relating to clothing lifetimes, particularly through emotional longevity, it is not clear that the findings are scalable beyond the UK, particularly to emerging markets. Meanwhile there is an opportunity to learn more about clothing use and emotional longevity from the European studies, and these could be usefully extended into wider markets and cultural contexts.

If extending the lifetime of clothing is to be seen as a way to reduce the industry's environmental impact, further research is required to explore the challenging issue of developing new business models that support clothing longevity in favour of fast changing and low cost fashion, to identify the market and product contexts where these can be most impactful, and ultimately to explore the extent to which such changes actually result in changed patterns of consumption and disposal. The focus for this needs to address some key issues and limitations, such as understanding consumer perspectives; better measures of the impact of clothing lifetime as a contributor to both sustainability KPIs and commercial imperatives; identifying relevant sources of knowledge from within the supply chain, as well as investing in upskilling of current and future workers and understanding mechanisms through which skills and knowledge can be easily and effectively shared. Extended demonstrator projects that include research, environmental and user evaluation and financial modelling, are needed to appraise the combined sustainability, commercial and 
infrastructural implications of longer lasting clothing, potentially also in different cultural and market contexts. These could be as diverse in approach as supporting niche brands to experiment with new approaches to incorporating services such as leasing and upcycling into their business models, to large brands adopting technological and data management approaches to monitor changes in product performance over time and maintain wide-scale data about materials and product failure that could inform future design decisions.

In the meantime, retailers and brands can adopt some generic process improvements, such as early involvement of suppliers and service providers and creating multi-functional teams to define the problem and overcome issues of trust and knowledge sharing. Innovations in product lifetime testing, user-centred design that reflects normal clothing use and care, and communications with consumers need to be incorporated into new business models, including changes to the product-service mix, as these are essential components that themselves also lack an effective mandate.

\section{References}

Aage, T. and Belussi, F., 2008, From Fashion networks to design: creative networks in industrial districts, Industry and Innovation, 15 (5), 475-491.

Allwood, J., Laursen, S., Russell, S., \& Malvido de Rodriguez, C. (2008). An approach to scenario analysis of the sustainability of an industrial sector applied to clothing and textiles in the UK. Journal of Cleaner Production, 16, 1234-1246.

Annis, P. (ed.), 2012, Understanding and improving the durability of textiles, Woodhead Publishing, Oxford.

Armstrong, C. and LeHew, M., 2011. Sustainable Apparel Product Development: In Search of a New Dominant Social Paradigm for the Field Using Sustainable Approaches. Journal of Fashion Practice, 3 (1) 29-62.

Armstrong, C., Niinimäki, K., Kujala, S., Karell, E., and Lang, C., 2014, Sustainable product-service systems for clothing: exploring consumer perceptions of consumption alternatives in Finland, Journal of Cleaner Production, 2014, pp.1-10 available at http://tinyurl.com/zjhzd3l [accessed $7 / 7 / 14]$

Black, S., 2008, Eco-chic: The Fashion Paradox, Black Dog, London.

Brun, A. and Castelli, C., 2008, Supply Chain Strategy in the Fashion Industry: Developing a Portfolio Model Depending on Product, Retail and Brand, International Journal of Production Economics, $116,169-181$.

Cachon, P. and Swinney, R., 2011, The Value of Fast Fashion: Quick Response, Enhanced Design, and Strategic Consumer Behaviour, Management Science, 97 (4) 778-795.

Caniato, F., Caridi, M., Crippa, L., and Moretto, A., 2012. Environmental sustainability in fashion supply chains: An exploratory case based research, International Journal of Production Economics, 135 (2) 659-670

Cheng, J., Yeh, C., \& Tu, C. (2008). Trust and knowledge sharing in green supply chains. Supply Chain Management: An International Journal, 13, 283-295.

Claxton, S., Cooper, T., Hill, H. and Holbrook, K. (2015). Opportunities and challenges of new product development and testing for longevity in clothing. In Product Lifetimes And The Environment (PLATE) Conference Proceedings, 17-19 June - Nottingham, UK. Edited by T. Cooper, N. 
Braithwaite, M. Moreno, G. Salvia. Published by Nottingham Trent University: CADBE. Pp. 62-68. ISBN 978-0-9576009-9-7.

Cooper, T. (ed.), 2010, Longer Lasting Products: alternatives to the throwaway society, Farnham: Gower.

Cooper, T., Claxton, S., Hill, H., Holbrook, K., Hughes, M., Knox, A. and Oxborrow, L. (2014). Clothing Longevity Protocol. A report for WRAP, London. Available at: http://tinyurl.com/hdp4j5q [accessed 1.11.15]

Curwen, L. G., Park, J. and Sarkar, A. K., 2012. Challenges and Solutions of Sustainable Apparel Product Development: A Case Study of Eileen Fisher. Clothing and Textiles Research Journal_31 (1) 32-47.

Defra, 2011, Sustainable Clothing Roadmap Progress Report, Available at: http://tinyurl.com/zv8k4n5 [accessed 1.3.16]

Fisher, T., Cooper, T., Woodward, S., Hiller, A. and Goworek, H. (2008), Public Understanding of Sustainable Clothing, Defra, London.

Gam, H., Cao, H., Farr, C., and Heine, L., 2008. C2CAD: A sustainable apparel design and production model. International Journal of Clothing Science and Technology, 21 (4) 166-179.

H M Government, 2013, Prevention is Better than Cure: The role of waste prevention in moving to a more resource efficient economy, London, Defra.

Hong, P., Kwon, H.-B., \& Roh, J. (2009). Implementation of strategic green orientation in supply chain: An empirical study of manufacturing firms. European Journal of Innovation Management, 12, 512-532.

Huang, H., Liu, Z., Zhang, L., \& Sutherland, J. (2009). Materials selection for environmentally conscious design via a proposed life cycle environmental performance index. International Journal of Advanced Manufacturing Technology, 44, 1073-1082.

Khan, O., Christopher, M. and Creazza, A., 2012, Aligning Product Design with the Supply Chain: a Case Study, Supply Chain Management, an International Journal, 17 (3), 323-336.

Laitala, K., and Boks, C., 2012, Sustainable clothing design: use matters, Journal of Design Research, 10, (1-2), pp121-139

Laitala, K., and Klepp, I. G., 2011, Environmental improvement by prolonging clothing use period, Towards sustainability in the Textile and Fashion industry, Copenhagen, 26-27 $7^{\text {th }}$ April.

Leonard, A., 2008, The Story of Stuff. Available at http://tinyurl.com/5hbmtz [Accessed 1.11.15]

McDonough, W. and Braungart, M. (2002), Remarking the Way We Make Things: Cradle to Cradle, North Point Press, New York, NY.

McDonough, W., Braungart, M., Anastas, P.T. and Zimmerman, J.B. (2003), “Applying the principles of green engineering to cradle-to-cradle design", Environmental Science \& Technology, 37, pp. 435A-41A.

McLaren, A., Goworek, H., Cooper, T., Oxborrow, L., Hill, H., 2016, The effect of consumer attitudes on design for product longevity: The case of the fashion industry, Design Research Society 50th Anniversary Conference: Future-focused Thinking, Brighton, UK

Mintel Oxygen, 2011, Women's Fashion Lifestyles, May. Available at http://tinyurl.com/zpeofaj [Accessed 10.11.15]

Muton, F., 2012, Masterclass video: Overview of global fashion market trends, Ethical Fashion Forum. Available at http://tinyurl.com/zkdgwdt [Accessed 1.11.15]

Niinimäki, K., 2012, Proactive Fashion Design for Sustainable Consumption, The Nordic Textile Journal, 1: pp60-69 
Niinimäki, K. and Armstrong, C., 2013, From pleasure in use to preservation of meaningful memories: a closer look at the sustainability of clothing via longevity and attachment, International Journal or Fashion Design, Technoligy and Education, 6 (3), pp.190-199

Oxborrow, L. 2015, Future scenarios in UK apparel supply chains: A Disaggregative Delphi Study, Unpublished DBA Thesis, Nottingham Trent University.

Petersen, K., Handfield, R., \& Ragatz, G. (2005). Supplier integration into new product development: Coordination product, process and supply chain design. Journal of Operations Management, 23, 371-388.

Rauer, J. and Kaufmann, L., 2015, Mitigating external barriers to implementing green supply chain management, Journal of Supply Chain Management, 51 (2) 65-88.

Scheffer, M., 2012, Growth Regimes and Innovation in the Current Decade, in Shishoo, R., (Ed.) 2012, The Global Textile and Clothing Industry, Technological Advances and Future Challenges, Cambridge, Woodhead, pp 8-28.

Swink, M., Melnyk, S., Cooper, M.B. and Hartley, J., 2010, Managing Operations across the Supply Chain, New York: McGraw Hill.

WRAP, 2012, Valuing our Clothes: the true cost of how we design, use and dispose of clothing in the UK, WRAP: Banbury. Available at: http://tinyurl.com/cuqkyx8 [Accessed 1.11.15]

WRAP, 2013a, Clothing Longevity - Measuring Active Use. Available at http://tinyurl.com/itdfpbt [Accessed 1.11.15]

WRAP, 2013b, Evaluating the financial viability and resource implications for new business models in the clothing sector. Available at: http://tinyurl.com/h592dxv [Accessed 10.3.15]

WRAP, 2014, Development of an industry protocol on clothing longevity, WRAP, Banbury. Available at: http://tinyurl.com/jnjk3fa [Accessed 1.3.15]

\begin{abstract}
About the Authors:
Lynn Oxborrow is a Principal Lecturer at Nottingham Business School and has undertaken expensive research in the apparel supply chain, with specific reference to responsiveness, retail-supplier relationships and sustainability, following an initial career in clothing retail.

Stella Claxton is a Senior Lecturer in Fashion Business at Nottingham Trent University, following a fashion industry career in knitwear design and technology. A member of NTU's Sustainable Consumption Research group, she has participated in funded research projects on clothing longevity.
\end{abstract}

